\title{
WHAT THE PANDEMIC HAS TAUGHT US: A PRELIMINARY FINDING FROM MOOC DEVELOPMENT PROJECT IN DIETETIC EDUCATION
}

\author{
Mutiara Tirta P L Kusuma1), Latifah Alifiana Rahmawati1,2) \\ 1)Department of Nutrition and Health, Faculty of Medicine, \\ Public Health, and Nursing, Universitas Gadjah Mada, Yogyakarta \\ 2)Dompet Dhuafa Foundation, Branch Yogyakarta
}

\begin{abstract}
Background: Various teaching methods and digital learning platforms have been in use to support learning during the Covid-19 pandemic. We presented the preliminary findings from the development project of a massive open online course (MOOC) in dietetic education. The study aimed to illustrate the process that will allow methodological adoption in any health professional education institution.

Subjects and Method: An MOOC in dietetic education has been piloted between March and October 2021 in a state dietetic school in Yogyakarta. The overall study which aimed to evaluate the course quality, was qualitative in nature. This case study was a critical reflection from all lecturers and teaching assistants involved in the preparation and implementation stages. We used content analysis to examine the data from group discussions, documents, and reflective journals.

Results: There were 112 students enrolled in the course, most of them were dietetic students in their junior year. We used the MOOC platform provided by Universitas Gadjah Mada to run the 7-weeks courses (equal with 1 credit point). We utilized a flipped classroom model, in which all learning materials were provided way before class time. We also incorporated weekly quizzes with immediate feedback, interactive discussion forum, and gamification to promote active learning. Exam and assessment are underway, although the initial data shows challenges on facilitating large scale marking and feedback. Digital competency remains as a major challenge experienced by the lecturers. Conclusion: With respect to the platform usability, MOOC has been able to support learning during the pandemic. It has the potential as an exit strategy given its flexibility and ability to reach a wider population. Further studies are required to develop ways to ensure easy adoption of the system.
\end{abstract}

Keywords: massive open online course, dietetic education, education, COVID-19

\section{Correspondence:}

Mutiara T P L Kusuma. Department of Nutrition and Health, Faculty of Medicine, Public Health, and Nursing, Universitas Gadjah Mada. Jl Farmako, Sekip Utara, Yogyakarta 55281. Email: mutiara.tirta@gmail.com. Mobile: +62 81398803205. 